\title{
Obstetrical and Perinatal Complications after Assisted Reproduction: what matters is age, not the procedure
}

\author{
Gorka Barrenetxea ${ }^{1,2 *}$, Irene Romero ${ }^{1,3}$, Ricardo Celis', Jon Iker Arambarri' ${ }^{1-3}$, Eva Rodríguez ${ }^{1,3}$ and Julen \\ Barrenetxea $^{3}$
}

${ }^{1}$ Reproducción Bilbao, Assisted Reproduction Center, Bilbao, Spain

${ }^{2}$ University of the Basque Country (UPV / EHU), Bilbao, Spain.

${ }^{3}$ Osakidetza, Public Health Network Basque Country, Bilbao.

*Address for Correspondence: Gorka Barrenetxea, Full Professor of Gynecology and Obstetrics, University of Basque Country (UPV/EHU), Spain, Mobile: 00349461112 13; E mail: gbarrenetxea@reproduccionbilbao.es

Received: 22 August 2020; Accepted: 05 September 2020; Published: 08 September 2020

Citation of this article: Barrenetxea G, Romero I, Celis R, Arambarri Jl, Rodríguez E, et al. (2020) Obstetrical and Perinatal Complications after Assisted Reproduction: what matters is age, not the procedure. Res Int J Obst Gynecol. 1(1): 001-008. DOI: $10.37179 /$ rijog.000001.

Copyright: (C) 2020 Barrenetxea G, et al. This is an open access article distributed under the Creative Commons Attribution License, which permits unrestricted use, distribution, and reproduction in any medium, provided the original work is properly cited.

\footnotetext{
ABSTRACT

Background: Worldwide, an increasing number of children (1 out of 10 in some countries) are born to pregnancies achieved by applying assisted reproductive technology (ART).

It has been assumed that these pregnancies have a higher prevalence of both obstetric and neonatal complications compared to gestations achieved after natural reproduction (NR).

Objective: The purpose of this study was to evaluate and compare maternal obstetrical and perinatal complications between pregnancies achieved after ART and NP, in a setting in which a strict policy of single embryo transfer is followed.

Study design: This is an observational comparative study to assess obstetrical and perinatal outcomes involving 583 patients who achieved an ongoing pregnancy after ART, by using either autologous (AO) (363 women) or donated oocytes (DO) (220 women) at a University associated Assisted Reproduction Center, between January, 2016 and December, 2018.

Age of women at delivery, gestational length, type of delivery, birthweight of newborns and perinatal complications were registered and compared to 273 deliveries of pregnant women after NP clinically followed at our center.

Results: Due to strict single embryo transfer policy the rate of multiple pregnancies after ART $(1,38 \%)$ was comparable to that of gestations after NR (1,10\%) (OR: 1,25; 95\% CI 0,33-4,76).

In our series, the percentage of women aged 35 or older (AMA) and 40 and older (VAMA), was similar between women in the NR group $(59,34 \%$ and $17,22 \%)$ and those of the ART with autologous oocytes (AO) group $(57,85 \%$ and $13,77 \%)(p=0,759$ and $p=0,234)$. Age of women was significantly higher in women pregnant after ART-DO procedures.

The rate of preterm deliveries was 6,59\%, 3,58\% and 12,27\% for NR, ART-A0 and ART-DO respectively. Birthweight of neonates after ART-AO was significantly higher than after NR $(p=0,000)$ and after ART-DO $(p=0,000)$.
} 
Citation: Barrenetxea G, Romero I, Celis R, Arambarri Jl, Rodríguez E, et al. (2020) Obstetrical and Perinatal Complications after Assisted Reproduction: what matters is age, not the procedure. Res Int J Obst Gynecol. 1(1): 001-008.

DOI: $10.37179 /$ rijog.000001.

Pregnancy induced hypertension was more frequently diagnosed among ART-DO pregnancies. No differences were seen in other analyzed obstetrical and neonatal complications.

Cesarean section rate was significantly higher among AR pregnancies, especially among ART-DO gestations. The probability of delivering by CS is as much as twice (and even triple if we consider pregnancies achieved through ART-DO).

Conclusion: The higher obstetrical and neonatal complications traditionally associated with pregnancies achieved after ART is a consequence of factors other than the procedure itself. Whereas some factors (age of women) depend on the different social profile, others (such as the indiscriminate transfers of more than one embryo) should move us to a deep reflection and self-criticism.

Furthermore, infants born after ART have comparable or better perinatal outcome than those born after NR once multiple pregnancies are avoided by following a policy and, thus a rational use, of single embryo transfer. This is reassuring regarding the use of ART but, at the same time, reinforces the convenience of earlier pregnancies.

Keywords: ART, Natural pregnancies, NP, Multiple pregnancies, assisted reproduction, advanced maternal age, cesarean section, placental disorders, pregnancy induced hypertension, low birthweight, prematurity.

\section{Introduction}

Over the course of the last decades, a substantial number of children have been conceived after applying assisted reproductive technology (ART) procedures [1,2]. It has been generally assumed that pregnancies achieved after ART have a higher prevalence of obstetric and perinatal complications such as prematurity and low birthweight neonates and a higher prevalence of cesarean sections at delivery [3-7]. Such perinatal complications could be a direct consequence of the higher rate of multiple pregnancies. Twin pregnancies have a threefold greater perinatal death rate overall compared to singleton pregnancies $[8,9]$.

However, other factors, such as advanced maternal age (over 35 years of age, AMA), could be related to these complications. During the last years, a steadily increase of maternal age has been observed worldwide [10-13]. In Spain, more than $37 \%$ and $8 \%$ of deliveries occurred in the AMA and very advanced age (over 40 years of age, VAMA) groups respectively [14].

The purpose of this study was to evaluate and compare maternal obstetrical complications and the risk of prematurity, birthweight of neonates, morbidity and mortality and type of delivery between pregnancies achieved after ART and NP.

\section{Materials and Methods}

The present study is an observational analysis involving 583 patients who achieved an ongoing pregnancy after ART in a University associated Assisted Reproduction Center, Reproduction Bilbao between January 2016 and December 2018. Gestational age at delivery, type of delivery, birthweight of newborns and perinatal complications were registered and compared to 273 deliveries of pregnant women after NP clinically followed at our center. Data collection was approved by the institutional review board of the center.

Age of women, type of ART procedure, the use of either autologous or donated eggs, gestational age at delivery and type of delivery were assessed. Also, the hospitals where deliveries were attended, belonging either to public or private network, were evaluated. Some variables were analyzed both as continuous and categorical variables. In this setting maternal age at delivery of women was assessed as a continuous variable and as categorical defining women of AMA (35 years and older) and VAMA (40 years and older). Gestational age at delivery was also categorized and premature deliveries (less than 37 weeks of gestation) and very premature deliveries (less than 33 weeks of gestation) were defined.

Birth and infant outcomes included maternal pregnancy complications (gestational diabetes and pregnancy hypertension), placental complications (excessive bleeding, placenta previa, and abruptio placenta), mode of delivery (vaginal, cesarean), and infant sex were assessed. Stillbirth ( $\geq 22$ weeks of gestation) was also included into adverse fetal/neonatal outcomes.

\section{Statistical analysis}

Statistical comparisons of clinical parameters between ART and NP deliveries were performed by applying the Student's and ANOVA tests for quantitative continuous variables and chi-squared test $\left(\chi^{2}\right)$ for categorical variables. Odds ratios (OR) were also calculated defining the likelihood that the assessed events (premature deliveries, AMA, VAMA) occurred more frequently among ART pregnancies. The threshold for statistical significance was set to $\mathrm{p}<0,05$. SPSS 25.0 (IBM Corporation, Chicago, IL) was used for analyzing the data.

\section{Results}

Baseline maternal characteristics of the different assessed groups are presented in (Table 1a). Mean age of pregnant women after NR

Table 1a: Age of women at delivery depending on the type of reproduction. Description and statistical analysis.

\begin{tabular}{|c|c|c|c|c|c|}
\hline & $\mathrm{n}$ & Mean & SD & SEM \\
\hline Natural reproduction (NR) & 273 & 35,60 & 3,85 & 0,23 \\
\hline Assisted Reproduction (AR) & 583 & 37,51 & 4,44 & 0,18 \\
\hline AR-autologous oocytes & 363 & 35,53 & 3,47 & 0,18 \\
\hline AR-donated oocytes & 220 & 40,83 & 3,86 & 0,26 \\
\hline & SD: Standard deviation of the mean \\
\hline & SEM: Standard error of the mean \\
\hline & $\mathrm{t}^{*}$ & $\mathrm{p}$ & & \\
\hline & 6,110 & $\mathbf{0 , 0 0 0}$ & \\
\hline AR vs. NR & $-0,210$ & 0,835 & \\
\hline AR-AO vs. NR & 14,980 & $\mathbf{0 , 0 0 0}$ & \\
\hline AR-DO vs. NR & 17,180 & $\mathbf{0 , 0 0 0}$ & \\
\hline AR-DO VS. AR-AO & $t^{*}$ : Pearson's $t$ & \\
\hline & Bold: statistically significant \\
\hline
\end{tabular}


Citation: Barrenetxea G, Romero I, Celis R, Arambarri Jl, Rodríguez E, et al. (2020) Obstetrical and Perinatal Complications after Assisted Reproduction: what matters is age, not the procedure. Res Int J Obst Gynecol. 1(1): 001-008.

DOI: $10.37179 /$ rijog.000001.

Table 1b: Age of women at delivery categorized as AMA and VAMA.

\begin{tabular}{|c|c|c|c|c|c|c|c|c|}
\hline & $<35$ YEARS & 35-39 YEARS & $>39$ YEARS & Total & AMA & \multicolumn{3}{|l|}{ VAMA } \\
\hline Natural reproduction (NR) & 111 & 115 & 47 & 273 & $59,34 \%$ & $17,22 \%$ & & \\
\hline Assisted Reproduction (AR) & 170 & 212 & 201 & 583 & $70,84 \%$ & $34,48 \%$ & & \\
\hline AR-autologous oocytes & 153 & 160 & 50 & 363 & $57,85 \%$ & $13,77 \%$ & & \\
\hline \multirow[t]{3}{*}{ AR-donated oocytes } & 17 & 52 & 151 & 220 & $92,27 \%$ & $68,64 \%$ & & \\
\hline & \multicolumn{4}{|c|}{ AMA } & \multicolumn{4}{|c|}{ VAMA } \\
\hline & $x^{2}$ & $\mathrm{p}$ & OR & $95 \% \mathrm{CI}$ & c2 & $\mathrm{p}$ & $\mathrm{OR}$ & $95 \% \mathrm{CI}$ \\
\hline AR vs. NR & 11,151 & 0,0008 & 1,66 & $1,23-2,25$ & 26,920 & 0,0000 & 2,53 & $1,77-36,21$ \\
\hline AR-AO vs. NR & 0,1424 & 0,7059 & 0,94 & $0,68-1,29$ & 1,428 & 0,2321 & 0,77 & $0,50-158$ \\
\hline AR-DO vs. NR & 68,7333 & 0,0000 & 8,18 & $4,72-14,19$ & 134,034 & 0,0000 & 10,52 & $6,89-16,08$ \\
\hline AR-DO VS. AR AO & 78,5703 & 0,0000 & 8,70 & $5,09-14,88$ & 182,510 & 0,0000 & 13,7 & $9,07-20,70$ \\
\hline
\end{tabular}

AMA: advanced maternal age (35 years and older)

VAMA: very advanced maternal age (40 years and older).

Bold: statistically significant

was significantly lower than women who achieved a gestation after AR. However, the advanced age of women in this AR setting was due mainly to those who followed a treatment by using donated oocytes. Moreover, if we analyze the percentage of women aged 35 or older (AMA) and those aged 40 and older (VAMA), it is worthy to observe that there were no differences between women in the NR group and those assigned to the IVF autologous group (pregnancy achieved after an IVF procedure by using own oocytes) (Table 1b).

One of the concerns regarding perinatal complications among gestations achieved after AR procedures is the high percentage of multiple pregnancies. During the study period (January,2016December,2018) we followed a strict single embryo transfer (sET) policy. Furthermore, in 2017 we decided to perform only sET. Therefore, the rate of multiple pregnancies after AR was low and comparable to that of gestations after NR (Table 2).

The mean gestational age at delivery was $39,31 \pm 0,14$ weeks (mean \pm standard error of the mean) for NR, 39,49 $\pm 0,10$ weeks for AR, $39,90 \pm 0,10$ for IVF with autologous oocytes and $38,82 \pm 0,21$ weeks for procedures in which donated eggs were used. The statistical analysis of the differences is presented in (Table 3).

(Table 4) shows the weeks of gestation at delivery depending on the different analyzed reproduction groups. The rate of preterm deliveries ( $<37$ weeks) among IVF pregnancies with autologous oocytes was inferior to the frequency among NR gestations. Overall, the risk of a preterm delivery was higher among pregnancies achieved with donated oocytes compared to NR (twice) and IVF with own oocytes (almost 4 times).

Birthweights of newborns are presented in (Table 5). Overall, the weight of newborns after AR procedures (including $1^{\text {st }}$ and $2^{\text {nd }}$ siblings) was not different to the newborns delivered after a NR pregnancy. However, after IVF performed with own (autologous) oocytes the birthweight of neonates was significantly higher than those delivered after NR $(p=0,000)$ and those after procedures with donated oocytes $(\mathrm{p}=0,000)$. Furthermore, the birthweight of newborns after using donated eggs was also inferior to the corresponding figure after NR pregnancies $(\mathrm{p}=0,014)$. Regarding newborns weighing less than 1000 g. (Table 6) there were no differences between NR and AR.
Table 2: Frequency of multiple deliveries according to the type of reproduction.

\begin{tabular}{|c|c|c|c|c|c|}
\hline \multicolumn{5}{c}{ MUTIPLE PREGNANCIES } \\
\hline & $\mathrm{n}$ & \multicolumn{2}{c|}{ Total } & $\%$ & \multicolumn{2}{c|}{ OR (95\% CI) } \\
\hline $\begin{array}{c}\text { Natural reproduction } \\
\text { (NR) }\end{array}$ & 3 & 273 & $1,10 \%$ & 1 & \\
\hline $\begin{array}{c}\text { Assisted Reproduction } \\
\text { (AR) }\end{array}$ & 8 & 583 & $1,37 \%$ & 1,25 & $0,33-4,76$ \\
\hline $\begin{array}{c}\text { AR-autologous oocytes } \\
\text { AR-donated oocytes }\end{array}$ & 5 & 363 & $1,38 \%$ & 1,26 & $0,30-5,11$ \\
\hline AR-donn & 3 & 220 & $1,36 \%$ & 1,24 & $0,25-6,23$ \\
\hline
\end{tabular}

Table 3: Gestational age at delivery depending on type of reproduction. Description and statistical analysis.

\begin{tabular}{|c|c|c|c|c|}
\hline & Mean & SD & SEM \\
\hline Natural reproduction (NR) & 39,31 & 2,24 & 0,136 & 273 \\
\hline Assisted Reproduction (AR) & 39,49 & 2,45 & 0,102 & 583 \\
\hline AR-autologous oocytes & 39,90 & 1,86 & 0,098 & 363 \\
\hline AR-donated oocytes & 38,82 & 3,10 & 0,211 & 220 \\
\hline
\end{tabular}

SD: Standard deviation

SEM: Standard error of means.

\begin{tabular}{|c|c|c|c|c|}
\hline & $\mathrm{t}^{*}$ & $\mathrm{p}$ & & \\
\hline AR vs. NR & 1,030 & 0,3037 & & \\
\hline AR-AO vs. NR & 3,620 & $\mathbf{0 , 0 0 0 0}$ & & \\
\hline AR-DO vs. NR & $-2,030$ & $\mathbf{0 , 0 4 2 4}$ & \\
\hline AR-DO VS. AR AO & $-5,260$ & $\mathbf{0 , 0 0 0 0}$ & \\
\hline
\end{tabular}

\section{$t^{*}$ : Pearson's $t$}

Bold: statistically significant

Obstetrical complications such as pregnancy induced hypertension (PIH), placental disorders (including abruptio and placenta previa), premature rupture of membranes (PROM) and intrauterine growth retardation (IUGR) are presented in (Table 7). Also, neonatal complications including admission to Neonatal Intensive Care Unit (NICU) and fetal malformations are showed in the same table. There were 4 stillbirths ( 2 in pregnancies achieved after IVF with autologous oocytes and 2 in procedures in which donated 
Citation: Barrenetxea G, Romero I, Celis R, Arambarri Jl, Rodríguez E, et al. (2020) Obstetrical and Perinatal Complications after Assisted Reproduction: what matters is age, not the procedure. Res Int J Obst Gynecol. 1(1): 001-008.

DOI: $10.37179 /$ rijog.000001.

Table 4a: Gestational age at delivery categorized into very preterm (33 weeks), preterm, term and posterm pregnancies.

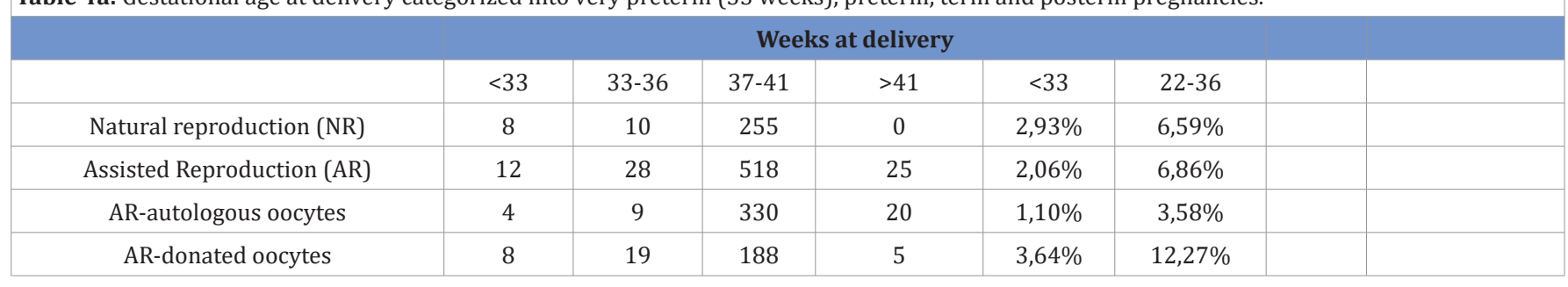

Table 4b: Statistical analysis of frequencies of preterm ( $<37$ weeks of gestation) and very preterm (33 weeks of gestation) deliveries.

\begin{tabular}{|c|c|c|c|c|c|c|c|c|}
\hline & \multicolumn{3}{|c|}{ PRETERM DELIVERY (22-36 WEEKS) } & \multicolumn{3}{c|}{ VERY PRETERM DELIVERY (<33 WEEKS) } \\
\hline & $\chi 2$ & $\mathrm{p}$ & $\mathrm{OR}$ & $95 \% \mathrm{CI}$ & $\chi 2$ & $\mathrm{p}$ & OR & $95 \% \mathrm{CI}$ \\
\hline & 0,021 & 0,8845 & 1,04 & $0,59-1,86$ & 0,620 & 0,4312 & 0,70 & $0,28-1,72$ \\
\hline AR vs. NR & 3,049 & 0,0808 & 0,53 & $0,25-1,09$ & 2,814 & 0,0934 & 0,37 & $0,11-1,24$ \\
\hline AR-AO vs. NR & 4,737 & 0,0295 & 1,97 & $1,06-3,68$ & 0,193 & 0,6601 & 1,25 & $0,46-3,39$ \\
\hline AR-DO vs. NR & 15,293 & $\mathbf{0 , 0 0 0 1}$ & 3,75 & $1,89-7,43$ & 4,365 & $\mathbf{0 , 0 3 6 7}$ & 3,39 & $1,01-11,38$ \\
\hline AR-DO VS. AR AO & \multicolumn{3}{|c|}{ Bold: statistically significant } & & & & & \\
\hline
\end{tabular}

Table 5: Birth weight of newborns (description and statistical analysis).

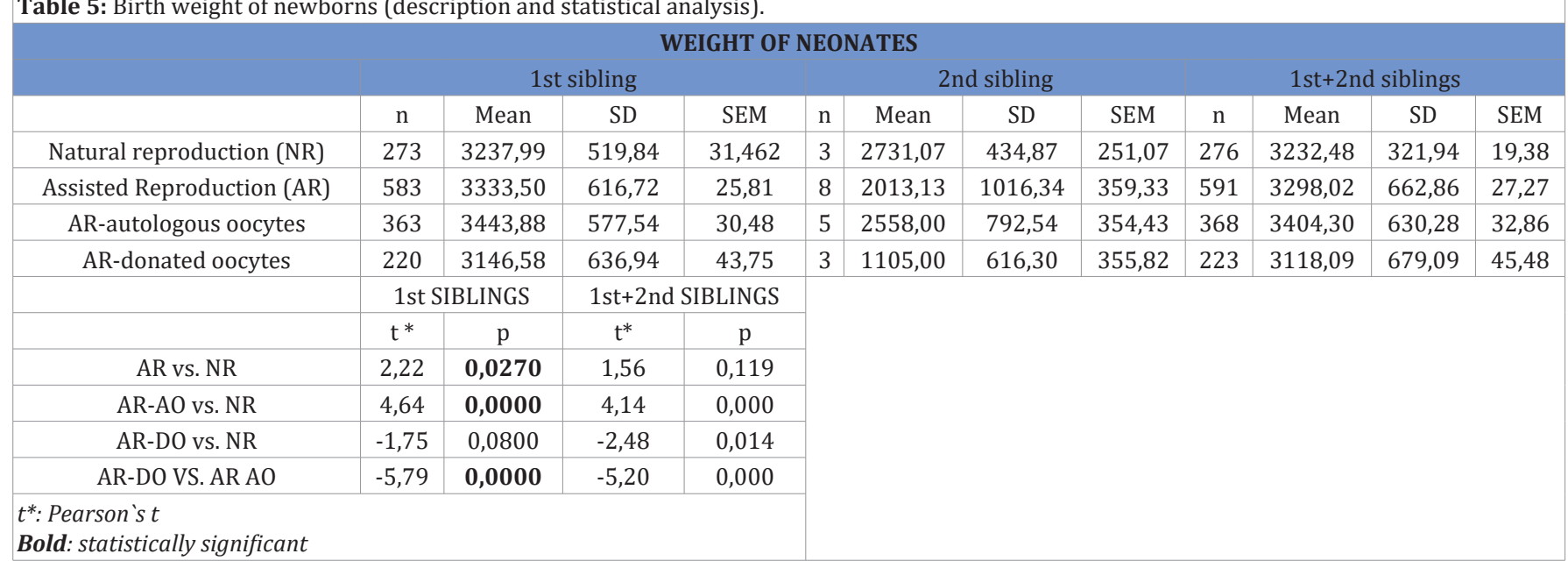

Table 6: Statistical comparisons of newborns weighing less than $1000 \mathrm{~g}$ depending on the type of reproduction.

\begin{tabular}{|c|c|c|c|c|c|c|c|c|c|}
\hline & \multicolumn{3}{|c|}{ 1st sibling $(<1000 \mathrm{G})$} & \multicolumn{3}{|c|}{ 2nd sibling (<1000 G) } & \multicolumn{3}{|c|}{ 1st+2nd siblings $(<1000 \mathrm{G})$} \\
\hline & $\mathrm{N}$ & $<1000 \mathrm{G}$ & $\%$ & $\mathrm{~N}$ & $<1000 \mathrm{G}$ & $\%$ & $\mathrm{~N}$ & $<1000 G$ & $\%$ \\
\hline Natural reproduction (NR) & 273 & 3 & $1,10 \%$ & 3 & 0 & $0,00 \%$ & 276 & 3 & $1,09 \%$ \\
\hline Assisted Reproduction (AR) & 583 & 5 & $0,86 \%$ & 8 & 2 & $25,00 \%$ & 591 & 7 & $1,18 \%$ \\
\hline AR-autologous oocytes & 363 & 0 & $0,00 \%$ & 5 & 0 & $0,00 \%$ & 368 & 0 & $0,00 \%$ \\
\hline \multirow[t]{3}{*}{ AR-donated oocytes } & 220 & 5 & $2,27 \%$ & 3 & 2 & $66,67 \%$ & 223 & 7 & $3,14 \%$ \\
\hline & \multicolumn{2}{|c|}{ 1st sibling } & \multicolumn{2}{|c|}{ 1st+2nd siblings } & & & & & \\
\hline & OR & $95 \% \mathrm{Cl}$ & OR & $95 \% \mathrm{Cl}$ & & & & & \\
\hline AR VS. NR & 0,78 & $0,18-3,28$ & 1,09 & $0,28-4,25$ & & & & & \\
\hline AR-AO vs. NR & nd & nd & nd & nd & & & & & \\
\hline AR-DO vs. NR & 2,09 & $0,49-8,86$ & 2,95 & $0,75-11,54$ & & & & & \\
\hline AR-DO VS. AR AO & nd & nd & nd & nd & & & & & \\
\hline
\end{tabular}

oocytes were required). No antepartum fetal demises were diagnosed among NR gestations. Besides fetal death, only PIH was more often diagnosed among AR pregnancies than NR gestations (Table 7).

Concerning the type of delivery (vaginal delivery vs. cesarean section), the frequency of CS was significantly higher among pregnancies achieved after AR, both IVF with own oocytes and by using donated eggs (Table 8). The probability (odds) of delivering by $\mathrm{CS}$ is as much as twice (and even triple if we consider pregnancies 
Citation: Barrenetxea G, Romero I, Celis R, Arambarri Jl, Rodríguez E, et al. (2020) Obstetrical and Perinatal Complications after Assisted Reproduction: what matters is age, not the procedure. Res Int J Obst Gynecol. 1(1): 001-008.

DOI: $10.37179 /$ rijog.000001.

Table 7: Obstetrical and perinatal disorders depending on the type of reproduction.

\begin{tabular}{|c|c|c|c|c|c|c|c|c|c|c|c|c|}
\hline & $\mathrm{PIH}$ & Plac. Dis. & PROM & IUGR & $\begin{array}{c}\text { Fetal } \\
\text { demise }\end{array}$ & NUCI & \multicolumn{6}{|c|}{ MALFORMATION } \\
\hline $\begin{array}{l}\text { Natural reproduction } \\
\text { (NR) }\end{array}$ & 4 & 2 & 6 & 1 & 0 & 3 & 2 & & & & & \\
\hline $\begin{array}{c}\text { Assisted Reproduction } \\
\text { (AR) }\end{array}$ & 30 & 12 & 13 & 9 & 4 & 2 & 3 & & & & & \\
\hline AR-autologous oocytes & 13 & 7 & 9 & 4 & 2 & 1 & 3 & & & & & \\
\hline \multirow[t]{3}{*}{ AR-donated oocytes } & 17 & 5 & 4 & 5 & 2 & 1 & 0 & & & & & \\
\hline & \multicolumn{2}{|r|}{$\mathrm{PIH}$} & \multicolumn{2}{|c|}{ Plac. Dis. } & \multicolumn{2}{|c|}{ PROM } & \multicolumn{2}{|c|}{ IUGR } & \multicolumn{2}{|r|}{ NUCI } & \multicolumn{2}{|c|}{ MALFORMATION } \\
\hline & OR & $95 \% \mathrm{CI}$ & OR & $95 \% \mathrm{CI}$ & OR & $95 \% \mathrm{CI}$ & OR & $95 \% \mathrm{CI}$ & OR & $95 \% \mathrm{CI}$ & OR & $95 \% \mathrm{CI}$ \\
\hline AR VS. NR & 3,65 & $\begin{array}{l}1,27- \\
10,46\end{array}$ & 2,85 & $\begin{array}{l}0,63- \\
12,81\end{array}$ & 1,01 & $\begin{array}{l}0,38- \\
2,70\end{array}$ & 4,20 & $\begin{array}{l}0,53- \\
32,98\end{array}$ & 0,31 & $0,05-1,86$ & 0,70 & $0,12-4,22$ \\
\hline AR-AO vs. NR & 2,50 & $0,81-7,75$ & 2,66 & $\begin{array}{l}0,55- \\
12,93\end{array}$ & 1,13 & $\begin{array}{l}0,40- \\
3,22\end{array}$ & 3,02 & $\begin{array}{l}0,34- \\
27,17\end{array}$ & 0,25 & $0,03-2,40$ & 1,13 & $0,19-6,80$ \\
\hline AR-DO vs. NR & 5,63 & $\begin{array}{l}1,87- \\
16,69\end{array}$ & 3,15 & $\begin{array}{l}0,61- \\
16,40\end{array}$ & 0,82 & $\begin{array}{l}0,23- \\
2,96\end{array}$ & 6,30 & $\begin{array}{l}0,73- \\
54,35\end{array}$ & 0,41 & $0,04-3,98$ & & \\
\hline AR-DO VS. AR AO & 1,54 & $0,83-2,86$ & 1,18 & $\begin{array}{l}0,37- \\
3,77\end{array}$ & 0,73 & $\begin{array}{l}0,22- \\
2,39\end{array}$ & 2,09 & $0,55-7,86$ & 1,65 & $\begin{array}{l}0,10- \\
26,56\end{array}$ & & \\
\hline \multicolumn{13}{|c|}{$\begin{array}{l}\text { PIH: Pregnancy induced hypertension, } \\
\text { Plac. Dis: placental disorders including placenta previa and abruptio. } \\
\text { PROM: premature rupture of membranes } \\
\text { IUGR: Inrauterine growth retardation. } \\
\text { Fetal demise: antenatal fetal death. }\end{array}$} \\
\hline
\end{tabular}

Table 8: Mode of delivery. Table of frequencies and statistical analysis.

\begin{tabular}{|c|c|c|c|c|c|c|c|}
\hline \multicolumn{7}{|c|}{ MODE OF DELIVERY } \\
\hline & VAGINAL & CESAREAN S. & & \\
\hline $\begin{array}{c}\text { Natural } \\
\text { reproduction } \\
\text { (NR) }\end{array}$ & 221 & $80,95 \%$ & 52 & $19,05 \%$ & 273 & 1 & \\
\hline $\begin{array}{c}\text { Assisted } \\
\text { Reproduction } \\
\text { (AR) }\end{array}$ & 390 & $66,90 \%$ & 193 & $33,10 \%$ & 583 & $\mathbf{2 , 1 0}$ & $\mathbf{1 , 4 9 - 2 , 9 8}$ \\
\hline $\begin{array}{c}\text { AR-autologous } \\
\text { oocytes }\end{array}$ & 255 & $70,25 \%$ & 108 & $29,75 \%$ & 363 & $\mathbf{1 , 8 0}$ & $\mathbf{1 , 2 4 - 2 , 6 2}$ \\
\hline $\begin{array}{c}\text { AR-donated } \\
\text { oocytes }\end{array}$ & 135 & $61,36 \%$ & 85 & $38,64 \%$ & 220 & $\mathbf{2 , 6 8}$ & $\mathbf{1 , 7 8 - 4 , 0 2}$ \\
\hline & $\begin{array}{c}\text { Bold: statistically } \\
\text { significant }\end{array}$ & & & & \\
\hline
\end{tabular}

Table 9: Type of delivery depending on the hospital (public vs. Private settings).

\begin{tabular}{|c|c|c|c|c|c|c|c|}
\hline \multicolumn{3}{|c|}{ VAGINAL } & \multicolumn{5}{|c|}{ CESAREAN S. } \\
\hline & $\mathrm{N}$ & $\%$ & $\mathrm{~N}$ & $\%$ & & OR & $95 \% \mathrm{CI}$ \\
\hline $\begin{array}{l}\text { PUBLIC } \\
\text { SETTING }\end{array}$ & 408 & $76,55 \%$ & 125 & $23,45 \%$ & 533 & 1,00 & \\
\hline \multirow[t]{3}{*}{$\begin{array}{l}\text { PRIVATE } \\
\text { SETTING }\end{array}$} & 206 & $63,78 \%$ & 117 & $36,22 \%$ & 323 & 1,85 & $\begin{array}{c}1,37 \text { to } \\
2,51\end{array}$ \\
\hline & \multicolumn{6}{|c|}{$\begin{array}{l}\text { Mode of delivery depending on the type of hospital } \\
\text { (Public vs. Private). }\end{array}$} & \\
\hline & $\chi 2=15,55$ & $(\mathrm{p}=0,000)$ & & & & & \\
\hline
\end{tabular}

achieved through donated oocytes), even after controlling for potential confounders. In this context, it is worth pointing out the differences between hospitals of public and private settings. The probability of delivering after a CS is almost double in private hospitals (Table 9).

\section{Discussion}

In this study we compared both, maternal obstetrical complications, and neonatal outcomes of newborns between pregnancies achieved after ART procedures and NR.

Newborns after ART procedures are increasing accounting for 9\% of all births in Spain in 2017 [15], a proportion that has doubled since 2010. Traditionally, pregnancies achieved by ART have been associated with a higher incidence of both maternal and neonatal complications. An unresolved issue is how much of the risk is due to infertility itself and underlying factors associated to infertility or the ART procedures used to achieve a gestation [16-19].

One of the key factors regarding perinatal outcomes of pregnancies is the age of women. In Spain, mean maternal age at first delivery has risen from 25,2 years in 1975 to 32,2 years in 2018 [13] through 30,7 in 2016 [12]. In 2018, 37,65\% of deliveries were among mothers above 35 years and $7,79 \%$ over 40 years $[12,13]$. Different factors such as difficulties in conciliating, a delayed economic independence present in western countries are the responsible of the delayed motherhood. Pregnancy complications such as placental disorders, gestational diabetes, pregnancy induced hypertension and intrauterine growth retardation are more common in older pregnant women [20, 21]. In our series, women pregnant after ART were older than those who achieved a pregnancy by NR, but the difference was based on those who achieved a pregnancy by using donated eggs. Moreover, there were no differences in age comparing women pregnant after IVF with autologous oocytes and those pregnant after NR.

One of the sources of perinatal complications (especially 
those related with prematurity and low birth-weight) is the higher percentage of multiple pregnancies associated with ART. Whereas the multiple pregnancy rate after ART was 14\% in Spain in 2017 [15], the figure for general population was $2 \%$ (13). Multiple pregnancies are associated with significant maternal and perinatal complications [22].

The mean gestational age at delivery in a recently reported study were $37,6 \pm 2,2($ mean $\pm S D), 35,2 \pm 2,7$ and $32,1 \pm 3,1$ week in singletons, twins, and triplets, respectively. The overall risk of preterm birth (less than 37 weeks of gestation) increased from 17,38\% among singletons to $64,94 \%$ among twins and $98,41 \%$ among triplets [2]. The corresponding figures in Spain were $13,27 \%, 55,78 \%$ and $96,88 \%$ for singletons, twins, and triplets respectively [15].

Because of our strict policy of single embryo transfer (sET) multiple pregnancy rate in our series was low and completely comparable to the corresponding figure after NR. It was demonstrated that the sET policy resulted in a significant reduction in the multiple pregnancy rate from $24 \%$ to $12 \%$ in Belgium [22] without a negative impact on the cumulative pregnancy rate $[23,24]$.

Nevertheless, it has been reported that pregnancies utilizing ART have a higher prevalence of prematurity and low birthweight of newborns, even in singleton gestations compared to pregnancies after NR $[7,25,26]$. Our data show that infants both in the AR and the NR groups were born at similar gestational ages. Moreover, regarding IVF with autologous oocytes, duration or pregnancies was even higher compared to NR pregnancies. Therefore, no differences were found in the birthweight of infants after NR compared to those after IVF with autologous oocytes.

The association between prematurity and advanced maternal age remains controversial. Fuchs et al [10] found that advanced maternal age (40 years or more) was associated with an increased risk of preterm birth even after adjustment for confounders. In their series, the lowest risk of prematurity was found among mothers aged 30-34 years. Although it has been reported that prematurity among older women (40 years and above) is attributable to iatrogenic reasons, the analysis performed by Fuchs et al comparing spontaneous and iatrogenic prematurity does not confirm that hypothesis.

In a recent study, Nagata et al [27] reported an increased risk of maternal complications including pregnancy-induced-hypertension, placental disorders, need of blood transfusion and NICU admission even after controlling for maternal age and other potential confounders. Their findings were consistent with previous studies $[28,29]$.

Our results show a higher incidence of PIH among pregnancies achieved by using donated oocytes, although not statistically significant, placental disorders, including placenta previa and abruptio, and intrauterine growth retardation (IUGR) were more frequently diagnosed among ART pregnancies. Various studies tried to study the independent influence of advanced maternal age and ART on the appearance of PIH [30] but the evidence is still conflicting. In addition to being older (especially those who achieved a pregnancy by using donated oocytes) and of lower parity, sub fertile patients have a higher incidence of chronic disease (hypertension or diabetes for example) compared to their fertile counterparts, and are more likely to develop PIH, as well as placental complications [18] Moreover, ART placentas have been documented to have altered morphology and gene expression, which may result in compromised development $[31,32]$.

In our series, there were no differences in admission to NICU. This lack of differences was probably secondary to the low multiple pregnancy rate. Previous studies have reported two-fold and threefold increases in perinatal deaths among those born prior to 37 or 33 weeks of gestation underlining the importance multiple pregnancies and the major consequence, prematurity $[2,8]$.

No differences were seen regarding fetal malformations. Previous studies have shown that AR procedures increase the risk of congenital anomalies [33, 34]. Levi Setti et al. [19] reported higher rates of anomalies among babies born in Italy after ART compared with rates recorded by the European Surveillance of Congenital Anomalies (EUROCAT) but similar rates of anomalies when compared with infants conceived by infertile patients who did not undergo ART. Therefore, this increase has been attributed to infertility itself and underlaying factors associated to infertility rather than ART [19, 33]. In accordance with our results, Heo et al [6] demonstrated that the incidence of major congenital anomalies in infants born as singletons after IVF was not higher than that in those born after NP after adjusting for confounding factors. As pointed out by the authors and in accordance with our recent results, the more generalized use of preimplantation genetic screening procedures may contribute to a lower incidence of congenital anomalies after ART procedures [35, 36].

Finally, the greater odds of cesarean delivery among pregnancies achieved after ART compared to NR gestations in our series (33,10\% vs. $19,05 \%$ ) (OR 1,49; 95\% CI 1,49-2,98) are in accordance with previously reported studies $[4,5,37,38]$. Furthermore, considering the lack of differences in multiple pregnancy rates among assessed groups, the higher CS rate may be associated with underlying medical and obstetrical factors, including age [38, 39]. Conversely, the rates of cesarean section among singleton pregnancies reported by some authors [6] were no different regarding ART and NR pregnancies.

\section{Strengths and limitations}

A main strength of this study is that it included patients followed during the same period of study offering an opportunity to compare pregnancy and neonatal outcomes between pregnancies after assisted or natural reproduction without the high multiple pregnancy rate usually associated to assisted reproduction. Moreover, data on obesity, smoking and alcohol use, gestational weight gain, accurate gestational measurements, and type of delivery of all gestations were available.

Limitations of the study include the low number (compared to general population in Spain) of patients. Moreover, being a private medical center, the pregnant women followed might not represent faithfully the general population.

\section{Conclusion}

The higher obstetrical and neonatal complications traditionally associated with pregnancies achieved after ART is a consequence of factors other than the procedure itself. Whereas some factors (age of women) depend on the different social profile, others (such as the indiscriminate transfers of more than one embryo) should move us to a deep reflection and self-criticism. 
Furthermore, infants born after ART have comparable or better perinatal outcome than those born after NR once multiple pregnancies are avoided by following a policy and, thus a rational use, of single embryo transfer. This is reassuring regarding the use of ART but, at the same time, reinforces the convenience of earlier pregnancies.

\section{References}

1. De Geyter C, Calhaz-Jorge C, Kupka MS, Wyns C, Mocanu E, et al. (2020) ART in Europe, 2015: results generated from European registries by ESHRE. The European IVF-monitoring Consortium (EIM) for the European Society of Human Reproduction and Embryology (ESHRE). Human Rep Open 1: 1-17. Link: https://bit.ly/3h5Dp02

2. Zegers-Hochschild F, Schwarze JE, Crosby J, Musri C, Urbina MT, et al (2019) Assisted Reproductive Techniques in Latin America: The Latin American Registry, 2015. JBRA Assisted Reproduction 23: 143-153. Link: https://bit.ly/3lVr5Dy

3. Stern JE, Liu Ch, Cabral HJ, Richards EG, Coddington CC, et al. (2018) Birth outcomes of singleton vaginal deliveries to ART-treated, sub fertile, and fertile primiparous women. J Assist Reprod Gene 35: 15851593. Link: https://bit.ly/3h27YEf

4. Sullivan EA, Chapman MG, Wang YA, Adamson GD (2010) Populationbased study of cesarean section after in vitro fertilization in Australia. Birth 37: 184-191. Link: https://bit.ly/2ZbI7Ul

5. Stern JE, Liu C, Cabral H, Richards EG, Coddington CC, et al. (2018) Factors associated with the increased risk of cesarean delivery in ART pregnancies. Fertil Steril 110: 429-436. Link: https://bit.ly/3h33ZYe

6. Heo JS, Lee HJ, Lee MH, Choi CW (2019) Comparison of neonatal outcomes of very low birth weight infants by mode of conception: in vitro fertilization versus natural pregnancy. Fertil Steril 111: 962-970. Link: https://bit.ly/3brkb4k

7. Schieve LA, Meikle SF, Ferre C, Peterson HB, Jeng G, et al. (2002) Low and very low birth weight in infants conceived with use of assisted reproductive technology. N Engl J Med 346: 731-737. Link: https:// bit.ly/310xUHj

8. Murray SR, Bhattacharya S, Stock SJ, Pell JP, Norman JE (2019) Gestational age at delivery of twins and perinatal outcomes: a cohort study in Aberdeen, Scotland. V2. Welcome Open Res 4: 65. Link: https://bit.ly/2GnPilJ

9. Barrenetxea G, Martínez M, De Las Heras M, Arambarri JI, Axpe M, et al (2019) Lack of predictive value of ovarian reserve tests for pregnancy likelihood. The huge difference between quantity and quality. Am J Biomed Sci \& Res 133-141. Link: https://bit.ly/3bumWld

10. Fuchs F, Monet B, Ducruet T, Chaillet N, Audibert F (2018) Effect of maternal age on the risk of preterm birth: A large cohort study. PLoS One 13: e0191002. Link: https://bit.ly/332xtAf

11. Fitzpatrick KE, Tuffnell D, Kurinczuk JJ, Knight M (2016) Pregnancy at very advanced maternal age: a UK population-based cohort study. BJOG 124: 1097-1106. Link: https://bit.ly/3i4xl9P

12. Claramonte M, Barrabes EM, Garcia S, Gutiérrez, Serra B (2019) Impact of aging on obstetric outcomes: defining advanced maternal age in Barcelona. BMC Pregnancy and Childbirth 19: 342-352. Link: https://bit.ly/3i3bmjJ

13. Instituto Nacional de Estadística (INE) INEbase Movimiento natural de la población. Link: https://bit.ly/2QYU772

14. Lean SC, Derricott H, Jones RL, Heazell AEP (2017) Advanced maternal age and adverse pregnancy outcomes: a systematic review and metaanalysis. PLoS One 12: e0186287. Link: https://bit.ly/359W60q

15. Cuevas I, Prados F, Pons I, Andrés M, Sánchez-Castro L, et al. (2020)
Registro Nacional de Actividad-Registro de la Sociedad Española de Fertilidad de fecundación in vitro e inyección espermática intracitoplasmática. Años 2016 y 2017. Med Rep Embr Clin (MEDRE) 7: 5-15. Link: https://bit.ly/2QWWKGz

16. Sutcliffe AG, Ludwig M (2007) Outcome of assisted reproduction. Lancet 370: 351-359. Link: https://bit.ly/3btynd2

17. Kondapalli LA, Perales-Puchalt A (2013) Low birth weight: is it related to assisted reproductive technology or underlying infertility? Fertil Steril 99: 303-310. Link: https://bit.ly/3hWVU8F

18. Luke B, Brown MB, Wantman E, Seifer DB, Sparks AT, et al. (2019) Risk of prematurity and infant morbidity and mortality by maternal fertility status and plurality. J Assit Reprod and Genetics 36: 121-138. Link: https://bit.ly/32ZfQ14

19. Levi Setti PE, Moioli M, Smeraldi A, Cesaratto E, Menduni F, et al. (2016) Obstetric outcome and incidence of congenital anomalies in 2351 IVF/ICSI babies. J Assist Reprod Genet 33: 711-717. Link: https://bit.ly/2Dvtluv

20. Kenny LC, Lavender T, McNamee R, O’Neill SM, Mills T, et al. (2013) Advanced maternal age and adverse pregnancy outcome: evidence from a large contemporary cohort. PLoS one 8: e56583. Link: https:// bit.ly/32Zfr $1 X$

21. Salem YS, Levy A, Wiznitzer A, Holcberg G, Mazor M, et al. (2011) A significant linear association exists between advanced maternal age and adverse perinatal outcome. Archives of gynecology and obstetrics 283: 755-759. Link: https://bit.ly/2DAdEI4

22. Peeraer KM, D’Hooghe T, Vandoren C, Trybou J, Spiessens C, et al. (2016) RBM on line 35: 279-286. Link: https://bit.ly/2F14gOj

23. De Neubourg D, Bogaerts K, Blockeel C, Coetsier T, Delvigne A, et al. (2016) How do cumulative live birth rates and cumulative multiple live birth rates over complete courses of assisted reproductive technology treatment per woman compare among registries? Hum. Reprod 31: 93-99. Link: https://bit.ly/321De20

24. Peeraer K, Debrock S, Laenen A, De Loecker P, Spiessens C, et al. (2014) The impact of legally restricted embryo transfer and reimbursement policy on cumulative delivery rate after treatment with assisted reproduction technology. Hum. Reprod 29: 267-275. Link: https://bit. ly/3gX9NCs

25. Helmerhorst FM, Perquin DAM, Donker D, Keirse JNC (2004) Perinatal outcome of singletons and twins after assisted conception: a systematic review of controlled studies. BMJ 328: 261-266. Link: https://bit.ly/2ZbPDhX

26. Henningsen AKA, Pinborg A, Lidegaard Ø, Vestergaard C, Forman JL, et al. (2011) Perinatal outcome of singleton siblings born after assisted reproductive technology and spontaneous conception: Danish national sibling-cohort study. Fertil Steril 95: 959-963. Link: https:// bit.ly/3haT9zz

27. Nagata C, Yang L, Yamamoto-Hanada K, Mezawa H, Ayabe T, et al. (2019) Complications and adverse outcomes in pregnancy and childbirth among women who conceived by assisted reproductive technologies: a nationwide birth cohort study of Japan environment and children's study. BMC Pregnancy Childbirth 19: 77. Link: https:// bit.ly/2ZrsZ5B

28. Qin J, Liu X, Sheng X, Wang H, Gao S (2016) Assisted reproductive technology and the risk of pregnancy-related complications and adverse pregnancy outcomes in singleton pregnancies: a metaanalysis of cohort studies. Fertil Steril 105: 73-85. Link: https://bit. ly/2QXiu 55

29. Healy DL, Breheny S, Halliday J, Jaques A, Rushford D, Garrett C (2010) Prevalence and risk factors for obstetric haemorrhage in 6730 
Citation: Barrenetxea G, Romero I, Celis R, Arambarri Jl, Rodríguez E, et al. (2020) Obstetrical and Perinatal Complications after Assisted Reproduction: what matters is age, not the procedure. Res Int J Obst Gynecol. 1(1): 001-008.

DOI: $10.37179 /$ rijog.000001.

singleton births after assisted reproductive technology in Victoria Australia. Hum Reprod 25: 265-274. Link: https://bit.ly/356GIlO

30. Chan BC, Lao TT (2008) Effect of parity and advanced maternal age on obstetric outcome. International journal of gynecology and obstetrics: the official organ of the International Federation of Gynecology and Obstetrics 102: 237-241. Link: https://bit.ly/2QU9LAO

31. Nelissen ECM, Dumoulin JCM, Daunay A, Evers JLH, Tost J, et al. (2013) Placentas from pregnancies conceived by IVF/ICSI have a reduced DNA methylation level at the H19 and MEST differentially methylated regions. Hum Reprod 28: 1117-1126. Link: https://bit.ly/321Mqn2

32. Sakian S, Louie K, Wong EC, Havelock J, Kashyap S, et al. (2015) Altered gene expression of $\mathrm{H} 19$ and IGF2 in placentas from ART pregnancies. Placenta 36: 1100-1105. Link: https://bit.ly/3jP7WRV

33. Pinborg A, Henningsen AK, Malchau SS, Loft A (2013) Congenital anomalies after assisted reproductive technology. Fertil Steril 99: 327-332. Link: https://bit.ly/2ZcePoz

34. Wen J, Jiang J, Ding C, Dai J, Liu Y, et al. (2012) Birth defects in children conceived by in vitro fertilization and intracytoplasmic sperm injection: a meta-analysis. Fertil Steril 97: 1331-1337. Link: https:// bit.ly/2QZ7lkg
35. Karmon AE, Sullivan DY (2019) Good outcomes in small babies, and the elephant in the room. Fertil Steril 111: 887. Link: https://bit. ly/2QYnDdb

36. Barrenetxea G, Martínez E, De las Heras M, Gómez 0, Arambarri JI, et al. (2018) Systematic single embryo transfer after preimplantation genetic screening improves overall results (in terms of" normal" ongoing pregnancies) and should be widely implemented. Hum Rep 229. Link: https://bit.ly/3haWKh3

37. Romundstad LB, Romundstad PR, Sunde A, von During V, Skjaerven $\mathrm{R}$, et al. (2009) Assisted fertilization, and breech delivery: risks and obstetric management. Hum Reprod 24: 3205-3210. Link: https://bit. ly/3h2hWFP

38. Luke B, Gopal D, Cabral H, Stern JE, Diop H (2017) Pregnancy, birth, and infant outcomes by maternal fertility status: the Massachusetts Outcomes Study of Assisted Reproductive Technology. Am J Obstet Gynecol 217: 327. Link: https://bit.ly/3i2GXSz

39. Declercq E, Luke B, Belanoff C, Cabral H, Diop H, et al. (2015) Perinatal outcomes associated with assisted reproductive technology: the Massachusetts Outcomes Study of Assisted Reproductive Technologies (MOSART). Fertil Steril 103: 888-895. Link: https://bit.ly/3i6uUUq 